\title{
Sutureless Glueless Conjunctival Autograft for Primary Pterygium Surgery
}

\section{Ahmed Mostafa Ismail ${ }^{3, *}$ MSc, Abd Allah Alhusseiny Abdel Gawad ${ }^{1}$ MD , Riad Alzaher Hassan ${ }^{2}$ MD}

*Corresponding Author:

Ahmed Mostafa Ismail

Optic.chiasma@yahoo.com

Received for publication February 28, 2020; Accepted October 5, 2020; Published online October 5 2020.

Copyright 2020 The Authors published by Al-Azhar University, Faculty of Medicine, Cairo, Egypt. All rights reserved. This an openaccess article distributed under the legal terms, where it is permissible to download and share the work provided it is properly cited. The work cannot be changed in anyway or used commercially.

doi: 10.21608/AIMJ.2020.24542.1153

${ }^{1}$ Ophthalmology Department, Faculty of Medicine, Al-Azhar University, Cairo, Egypt.

${ }^{2}$ Ophthalmology Department, Faculty of Medicine, Al-Azhar University, Damietta, Egypt.

${ }^{3}$ Ophthalmology Department, Damietta Ophthalmology Hospital, Damietta, Egypt.

\begin{abstract}
Background: Pterygium is a fibrovascular growth of an abnormal conjunctival tissue that progressively encroaches the limbus and then onto the cornea invading its superficial layers. It is a common ophthalmic condition seen mostly in dry, dusty areas.

Aim of work: The aim of the current study was toevaluatethe sutureless glueless conjunctival autograft for primary pterygium surgery as regard technique, complications and success rate.

Patient and Methods: This prospective study included a total of 30 patients with primary nasal pterygium, attending at Outpatient Clinic of Ophthalmology Department, Al-Azhar University, Damietta.This study was conducted between March 2017 to March 2018.

Results: When comparing post-operative values at the end of third month with the first month we have found no difference in corneal state for all patients.The patient with corneal opacity was as the first month and had no difference in corneal state or BCVA. We detected one patient (3.3\%) having recurrent pterygium. Finally when comparing postoperative values at the sixth month with the third month, we havefound another patient who was reported with recurrent pterygium. Thus,the recurrence rate was 2 patients (6.7\%) among all studied patients and the other values were approximately the same.

Conclusion: This study suggests that sutureless glueless conjunctival autograft technique is a safe, simple, easy of performance, has less surgical time and very effective for the management of primary pterygium.
\end{abstract}

Keywords: Sutureless Glueless Conjunctival Autograft ; Pterygium.

Disclosure: The authors have no financial interest to declare in relation to the content of this article. The Article Processing Charge was paid for by the authors.

Authorship: All authors have a substantial contribution to the article.

\section{INTRODUCTION}

Pterygium occurs predominantly on the nasal limbus, although temporal pterygium rarely occurs in isolation. Double-head pterygium, that is nasal and temporal pterygia in the same eye is rare. In studies by Dolezalová, the incidence was found to be (2.5\%). ${ }^{1}$

UV light may produce damage to the cellular DNA, RNA, and extracellular matrix and may induce expression of cytokines and growth factors important in the development of pterygium. ${ }^{2}$

It was described that the pterygium was associated with human papilloma virus (HPV) with the predisposing factor as dry heat and it also behaves as

a neoplasm revealed by the presence of 8hydroxydeoxyguanosine in the pterygial tissue that suggested the role of oxidative stress as a key factor in its causation. ${ }^{3}$

The active processes unleashed include inflammation, tissue invasion and degradation,

angiogenesis, fibrosis, proliferation and apoptosis with involvement of matrix metalloproteinases (MMPs), cytokines, and growth factors (GFs). The presence of an inflammatory mass on the ocular surface may predispose the patient to a "pseudo-dry eye syndrome". 4

Conjunctival autografting after pterygium excision seems to be the best method, giving both long-term safety and effectiveness in reducing the recurrence rate $(2 \%-39 \%){ }^{5}$

The conjunctival autograft is attached with sutures, which may be associated with complicated surgical techniques, prolonged operating time, prolonged postoperative patient discomfort, and suture-related complications. ${ }^{6}$

Scanty data exists evaluating success of sutureless and glue free limbal conjunctival autograft for the 
management of primary pterygium. ${ }^{7}$ The results were very encouraging as they suggested that sutureless and glue free limbal conjunctival autografting following pterygium excision is a simple, safe, effective, without much complications and economical option for the management of primary pterygium. ${ }^{6}$

The aim of the current study was to evaluate the sutureless glueless conjunctival autograft for primary pterygium surgery as regard technique, complications and success rate.

\section{PATIENT AND MATERIALS}

This prospective study included a total of 30 patients with primary nasal pterygium, attending at Outpatient Clinic of Ophthalmology Department, AlAzhar University, Damietta.

Ethical approval:Written informed consent from all the subjects were obtained. This study was conducted between March 2017 to March 2018. Approval of the ethical committee was obtained.

Preoperative evaluation: (i) History taking: Onset, course and duration of pterygium formation progression. And history of any ocular trauma, ocular surgery, systemic disorder and drug intake. (ii) General examination:Review for systemic diseases as diabetes mellitus, hypertension, bleeding tendency and liver diseases. (iii) Laboratory investigation:Complete blood count (CBC), coagulation profile (CP), fasting plasma glucose, 2 hours postprandial blood glucose (PPG), liver and kidney function tests. (iv) Preoperative ophthalmological examination:All patients underwent complete ophthalmic examinations

\section{Surgical Technique:}

In the holding area topical anesthetic drops are started. We had used (Tetracaine $0.5 \%$ ) one drop to the designated eye. This gave the patient a chance to compare the sensation or lack of sensation between the two eyes. At the operating table the affected eye was cleaned and draped,and a second dose of topical anesthetic is instilled. This second dose is with (Xylocaine gel 4\%) which is considerably stronger and excellent for advancing anesthesia to the conjunctiva and the site of peribulbar anesthesia injection prior to the injection of Carbocaine.

The syringe with 5 cc of Carbocaine 2\% was brought slowly from the side, to minimize visibility by the operated eye. Then we injected Carbocaine peribulbarly by using 25-gauge needle which was slipped gently at infra orbital notch then pressing over the eye till complete akinesia was performed.

The upper face was prepped with Povidine Iodine 5\% solution and the designated eye draped. Care was taken to ensure adequate breathing space under the drape as there was no assisted oxygen provided in the office setting.

All surgeries were performed by one surgeon, firstly the wire speculum was applied over operated eye. The lid speculum was then inserted and the remainder. Also,ocular sterilization with a drop of Povidine Iodine $5 \%$ was used.
The initial incision was made into the body at a point (2-4 $\mathrm{mm}$ ) distal to the limbus which would generally involve most of the pterygium, then the body of pterygium was totally dissected in retrograde manner including conjunctiva and Tenon's capsule till reached the limbus.

Excision of the head after the incision into the body then removal only the affected tissue with the affected corneal part by using Colibri forceps in continuous circular technique.

We Measured the scleral area to be covered by caliber. When the area to be covered is less in size, the more successful the graft would be.

Then curettage was applied over sclera and excised corneal parts by using blade 15 or crescent blade till the sclera became avoided of conjunctiva and Tenon's capsule and the cornea became completely clear (B).

Harvesting the free graft done from the superior aspect of the conjunctiva. We used blunt dissection to avoid buttonholing the graft after marking the size of the graft.

The graft was excised from the upper bulbar conjunctiva by scissor through removing of conjunctiva and leaving Tenon's capsule after measured it later to measure of excised part and adding $1 \mathrm{~mm}$ over excised part.

The last part of graft to be removed was the limbal part by blade 15 or crescent blade. Then the scissor till removed totally (B)

Positioning the free graft done without it losing contact with the host surface. It is imperative to lay it flat on the moistened cornea with the sub conjunctival side down and then slide it into position on the scleral bed. The original limbal edge wasopposed to the cornea at the corresponding limbus. Stretch the graft at the limbus so it maintains contact. It was covered the exposed sclera entirely and slightly overlap the cut edges of the conjunctiva.

Fixation the free graft in place and applied over bare sclera by tying forceps and squeezing the graft by using hock about 5 minutes till be sure that it became stable.

Then wire speculum was removed carefully. Then the tight bandage was applied for next 48 hours without removal except during treatment.

After the operation all patients were received the same standard medications for 4 weeks, consisting of an eye drops combination of $(0.3 \%$ Tobramycin and $0.1 \%$ Dexamethasone) and antibiotic (Gatifloxacin $0.3 \%$ ) eye drops and tear substitutes beginning with five times daily and tapered gradually every 5 days.

Statistical analysis:The data were collected, coded, revised, verified, and computerized. Statistical analyses were done using SPSS statistical package

version 16. (IBM Corp, Chicago, IL, USA) Qualitative data were presented in the form of numbers and percentages and quantitative variables as mean and standard deviation (SD). A comparison between quantitative variables was carried out by the 
student T-test of two independent samples. Chisquare test (X2), was used to compare qualitative variables.

\section{RESULTS}

\begin{tabular}{|c|c|c|}
\hline & & Statistics \\
\hline \multirow{2}{*}{ Sex } & Male & $17(56.7 \%)$ \\
\hline & Female & $13(43.3 \%)$ \\
\hline \multicolumn{2}{|c|}{ Age (years) } & $41.23 \pm 7.07 ; 28-53$ \\
\hline \multirow{2}{*}{ Eye } & Right & $18(60.0 \%)$ \\
\hline & Left & $12(40.0 \%)$ \\
\hline \multirow{3}{*}{ Grade } & $\mathbf{I}$ & $6(20.0 \%)$ \\
\hline & II & $18(60.0 \%)$ \\
\hline & III & $6(20.0 \%)$ \\
\hline \multirow{3}{*}{ Refraction } & Sphere & $0.025 \pm 0.68 ;-1.0-1.25$ \\
\hline & Cylinder & $-0.52 \pm 0.28 ;-1.0-0.0$ \\
\hline & Axis & $78.10 \pm 60.93 ; 0.0-172.0$ \\
\hline \multirow{3}{*}{ UCVA } & $6 / 9$ & $21(70.0 \%)$ \\
\hline & $6 / 12$ & $6(20.0 \%)$ \\
\hline & $6 / 6$ & $3(10.0 \%)$ \\
\hline \multirow{2}{*}{ BCVA } & $6 / 9$ & $9(30.0 \%)$ \\
\hline & $6 / 6$ & $21(70.0 \%)$ \\
\hline \multicolumn{2}{|c|}{ IOP } & $14.86 \pm 1.54 ; 12.0-18.0$ \\
\hline
\end{tabular}

Table 1:Preoperative data among studied populations.

In the present work, $56.7 \%$ of studied populations were males and $43.3 \%$ were females. The patient age ranged from 28 to 53 years and the mean age was 41.23 years. The condition was on the right eye in $(60.0 \%)$ and on the left side in $(40.0 \%)$ of studied populations. The grade of disease was first in (20\%), second in $(60.0 \%)$ and third in (20.0\%). The patient UCVA was 6/9 in (70.0\%), 6/12 in (20.0\%) and 6/6 in (10\%), while the BCVA was $6 / 9$ in $(30.0 \%)$ and $6 / 6$ in $(70.0 \%)$ among studied populations. Finally, IOP ranged from 12 to 18 , and the mean IOP was $14.86 \mathrm{mmHg}$. As shown table (1).

\begin{tabular}{|c|c|c|}
\hline & & Statistics \\
\hline \multirow[t]{2}{*}{ Graft position } & In position & $28(93.3 \%)$ \\
\hline & $\begin{array}{r}\text { Displaced } / \\
\text { Fallen }\end{array}$ & $2(6.7 \%)$ \\
\hline \multirow[t]{2}{*}{ Graft edema } & Yes & $5(16.7 \%)$ \\
\hline & No & $25(83.3 \%)$ \\
\hline \multirow{2}{*}{$\begin{array}{c}\begin{array}{c}\text { Sub-graft } \\
\text { hemorrhage }\end{array} \\
\end{array}$} & Yes & $6(20.0 \%)$ \\
\hline & No & $24(80.0 \%)$ \\
\hline \multirow[t]{2}{*}{ Cornea } & Epithelial defect & $\begin{array}{r}30 \\
(100.0 \%)\end{array}$ \\
\hline & $\begin{array}{l}\text { Complete re- } \\
\text { epithelialization }\end{array}$ & $0(0.0 \%)$ \\
\hline $\begin{array}{r}\text { Early } \\
\text { complications }\end{array}$ & None & $\begin{array}{r}30 \\
(100.0 \%)\end{array}$ \\
\hline
\end{tabular}

Table 2:Results in the first postoperative day.

At the first postoperative day, (93.3\%) of grafts were in position while $(6.7 \%)$ were displaced partially; graft edema was reported in (16.7\%) and sub-graft hemorrhage was reported in (20.0\%). All studied corneas revealed epithelial defect and there were no early complications. As shown table (2).

\begin{tabular}{||c|c|c||}
\hline \multirow{2}{*}{ Cornea } & Clear & Statistics \\
\cline { 2 - 3 } & Cornealopacity & $1(3.3 \%)$ \\
\hline \multirow{2}{*}{ BCVA } & $\mathbf{6 / 9}$ & $6(20.0 \%)$ \\
\cline { 2 - 3 } & $\mathbf{6 / 6}$ & $24(80.0 \%)$ \\
\hline \multirow{2}{*}{ Fundus } & Normal & $30(100.0 \%)$ \\
\cline { 2 - 3 } & Abnormal & $0(0.0 \%)$ \\
\hline \multirow{2}{*}{ Recurrence } & Yes & $1(3.3 \%)$ \\
\cline { 2 - 3 } & No & $29(96.7 \%)$ \\
\hline \multirow{2}{*}{ IOP } & & $15.30 \pm 1.29 ; 13-17$ \\
\hline
\end{tabular}

Table 3: Results at the end of the sixth postoperative month.

At the end of the sixth postoperative months, the cornea still clear in (96.7\%), while corneal opacity was reported in (3.3\%); the BCVA was $6 / 9$ in (20.0\%) and 6/6 in (80.0\%); the fundus was normal in all cases and the recurrence rate was reported (6.7\%). The IOP ranged from 14-17; the mean value was $15.30 \mathrm{mmHg}$. As shown table (3).

\section{DISCUSSION}

In this study, all patients underwent sutureless glueless graft after primary nasal pterygium excision. (43.3\%) of patients were female and $(56.7 \%)$ were male. (60\%) of patients were with their right eye and (40\%) were with left eye. The grade of pterygium ranged between (I), (II) and (III). The patient age ranged from (28 to 53) yeas and the mean age was (41.23) years.

According to treatment, surgical excision, which is the treatment of choice for pterygium, can be divided into 2 types: simple excision (the bare-sclera technique) and excision with grafting (conjunctival or amniotic membrane grafting). Recurrence is the most common undesirable outcome of pterygium excision. Several factors increase the recurrence rate after surgery, such as the activity of the pterygium. ${ }^{8}$

We had performed "sutureless glueless graft" under local anesthesia using firstly (Tetracaine $0.5 \%$ ) one drop to the designated eye thens second dose of topical anesthetic is instilled. This second dose was with (Xylocaine gel 4\%) which was considerably stronger and excellent for advancing anesthesia to the conjunctiva and the site of peribulbar anesthesia injection. Xylocaine gel $4 \%$ reduces pain and burning discomfortthat resulting from infiltration of the skin and subcutaneous tissues with local anesthetic solutions, which is often severe enough to be the most unpleasant part of a surgical procedure especially for patients with needle phobia. After that we injectedperibulbar (Carbocaine 2\%) to achieve complete akinesia. The Long-lasting anesthesia with peribulbar anesthesia permitted performing our 
surgical procedure with low pain perceived by patients, minimally invasive surgery, prevention of graft displacement during surgery and hence short duration of surgery. Then followed by cleaning and sterile draping.

In 2018 there was a study comparing the efficacy of different concentrations of topical lidocaine gel with standard subconjunctival anesthesia. They enrolled 45 consecutive patients with 3 different groups who underwent primary pterygium surgery. Group 1 received subconjunctival lidocaine and proparacaine drops as needed during surgery. Group 2 received $2 \%$ lidocaine gel and group 3 received 5\% lidocaine gel. And they demonstrated that the use of lidocaine gel at concentrations of $2 \%$ and $5 \%$ in pterygium surgery was as effective as subconjunctival injection of lidocaine in reducing intraoperative and postoperative pain, producing significantly less pain during initial administration of the anesthetic. ${ }^{9}$

We applied in our technique topical local anesthesia drops using (Tetracaine 0.5\%) with (Xylocaine gel 4\%) and peribulbar injection (Carbocaine 2\%) to achieve complete akinesia during surgery. We noticed the efficacy of this combination during our study in which there was no any complain of pain during the operation for all studied patients hence allowed us tooperate comfortably.

After the operation all patients were received the same standard medications for 4 weeks, consisting of an eye drops combination of $(0.3 \%$ Tobramycin and $0.1 \%$ Dexamethasone) and antibiotic (Gatifloxacin $0.3 \%$ ) eye drops and tear substitutes beginning with five times daily and tapered gradually.

At the end of the third postoperative month, the cornea was clear in (96.7\%) of studied subjects, while corneal opacity was reported in the previous one patient (3.3\%). The BCVA was 6/9 in (20\%) and $6 / 6$ in (80.0\%); the fundus was normal among all studied patients and the recurrence of pterygium was reported in one patient (3.3\%) among all patients. The IoP ranged from 13 to 17 and the mean value was $15.30 \mathrm{mmHg}$.

At the end of the sixth postoperative months, the cornea still clear in (96.7\%), while corneal opacity was reported in (3.3\%) in the same previous patient. the BCVA was $6 / 9$ in (20.0\%) and 6/6 in (80.0\%); the fundus was normal in all cases and there was recurrence in two eyes $(6.7 \%)$ among all studied patients with no increase in size of the pterygium case that reported at the end of the third postoperative month. The IOP ranged from 14-17; the mean value was $15.30 \mathrm{mmHg}$.

The advantages of "bare sclera technique" are easy procedure, has the least surgical time among all procedures and least post-operative discomfort. ${ }^{10}$ While the conjunctival flaps technique is a simple procedure which is the surgeon's preference and is recommended for all primaries, small recurrences and especially double-headed lesions. It features the same attached blood supply, blood vessels oriented vertically away from the limbus, ease of performance, fast healing and single wound. ${ }^{11}$

According to “conjunctival autograft” the technique is the surgeon's preference for primary degenerative pterygium in older eyes with thin conjunctiva and no glaucoma and for degenerative recurrences. In the absence of double headed pterygium and there may not be enough tissue available for the required two wounds, this procedure is considered by many surgeons to be the gold standard for prevention of recurrence after pterygium surgery. ${ }^{11}$

On the other wise "mucosal graft technique" is limited due to difficulty harvesting the mucosal tissue, the requirement of two wounds for healing, possible infection due to bacterial content, postoperative pain and high incidence of granuloma. $^{12}$

In some cases of "transposition technique", it may be cosmetically unacceptable but necessary to reduce the continued destruction of the cornea by the lesion. ${ }^{11}$

In our study, as regard "sutureless glueless graft technique" rather than the complications of peribulbar anesthesia as retrobulbar hemorrhage, optic neuropathy, globe penetration or perforation, the complications of the surgery may include complications that similar to the complications of conjunctival autograft with sutures or glue as the requirement of two wounds for healing, postoperative pain, epiphora and granuloma. It may also include early graft displaced or fallen with eye rubbing as that was reported during our study.

"The mucosal graft technique" features an average recurrence rate of (10 - 25\%) which is partly due to the severity of the lesion, a high inflammation response and relatively slow re-epithelialization during wound healing. ${ }^{11}$

In our study "sutureless glueless graft technique”, the rate of pterygium recurrence was $(6.7 \%)$ after following up during 6 months. But further controlled studies are needed to demonstrate the long-term outcomes of recurrence rate for this procedure because the 6 months is considered as a short period for judge the recurrence rate clearly.

\section{CONCLUSION}

It could be concluded that sutureless glueless conjunctival autograft technique is a safe, simple, easy of performance, has less surgical time and very effective for the management of primary pterygium.

We found that this procedure had no more complications associated with sutures and glueof other pterygium excision procedures, with less postoperative discomfort, fast healing and economical option for the management of primary pterygium surgery with the recurrence rate was (6.7\%).

Further controlled studies are needed to demonstrate the potential advantages and long-term outcomes of this procedure.

\section{REFERENCES}

1. Shreesha K K, Dandapani R, Nitin NT, et al. Double-head pterygium excision with modified vertically split-conjunctival autograft: Six-year 
long-term retrospective analysis. Indian $J$ ophthalmol.,2017; 65(8): 700-4.

2. Di GN, Wakefield D and Coroneo MT. UVBmediated induction of cytokines and growth factors in pterygium epithelial cells involves cell surface receptors and intracellular signaling. Invest ophthalmol Vis Scz.,2006; 47(6):2430-7.

3. Tsai YY, Cheng YW, Lee H, et al.Oxidative DNA damage in pterygium. Mol Vis.,2005; 11:71-5.

4. Li M, Zhang M, Lin Y,et al. Tear function and goblet cell density after pterygium excision. Eye,2007; 21(2):224- 8.

5. Ang LP, Chua JL and Tan DT, Current concepts and techniques in pterygium treatment. Curr opin ophthalmol.,2007; 18:308.

6. Xu F, Li M, Yan Y, et al. A novel technique0f sutureless and glueless conjunctival autografting inpterygium surgery by electrocautery pen.Cornea,2013; 32(3):290-5.

7. Malik KPS, Goel R, Gupta A, et al. Efficacy of suturelessand glue free limbal conjunctival autograft for primarypterygium surgery.Nepal $J$ ophthalmol.,2012; 4: 230-5.
8. Clearfield E, Muthappan V, Wang X, et al. Conjunctival autograft for pterygium. Cochrane Database Syst Rev., 2016; 11;2:CD011349.

9. Pereira F, Shiroma HF, Urias MG, et al. Pilot Study Comparing Topical Anesthetic Agents in Pterygium Surgery: Subconjunctival Injection Versus 2\% Lidocaine Gel Versus 5\% Lidocaine Gel. Cornea,2018; 37(2):194-8.

10. Hovanesian JA, Behesnilian AS. Pterygium excision with a conjunctival autograft and prophylactic placement of subconjunctival amniotic membrane surrounding the excision site. In: Hovanesian JA, editor. Pterygium: Techniques and Technologies for Surgical Success. Thorofare, NJ: Slack Incorporated, 2012; P. 101-10.

11. Alfred LA.Pterygium - A Practical Guide to Management. Jaypee Brothers Medical Publishers (P) Ltd., 2009. https://www.amazon.com/Pterygium-PracticalManagement-Alfred-Anduze/dp/8184487258,

12. Pherwani A, Vakil $\mathrm{V}$ and Eatamadi $\mathrm{H}$. Postoperative subconjunctival 5-fluorouracil in the management of recurring pterygium. $\mathrm{Br} J$ Ophthalmol., 2007;91:398-9. 